\title{
A Model for Analyzing a Five-Phase Fractional-Slot Permanent Magnet Tubular Linear Motor with Modified Winding Function Approach
}

\author{
Bo Zhang, ${ }^{1,2}$ Rong Qi, ${ }^{1}$ Hui Lin, ${ }^{1}$ and Julius Mwaniki ${ }^{1}$ \\ ${ }^{1}$ Department of Electrical Engineering, School of Automation, Northwestern Polytechnical University, Xian 710129, China \\ ${ }^{2}$ Department of Electrical Engineering, Electronic Information College, Xi'an Polytechnic University, Xi'an 710048, China \\ Correspondence should be addressed to Bo Zhang; paul8899@126.com
}

Received 16 March 2016; Revised 13 June 2016; Accepted 20 June 2016

Academic Editor: Bin-Da Liu

Copyright (C) 2016 Bo Zhang et al. This is an open access article distributed under the Creative Commons Attribution License, which permits unrestricted use, distribution, and reproduction in any medium, provided the original work is properly cited.

\begin{abstract}
This paper presents a model for analyzing a five-phase fractional-slot permanent magnet tubular linear motor (FSPMTLM) with the modified winding function approach (MWFA). MWFA is a fast modeling method and it gives deep insight into the calculations of the following parameters: air-gap magnetic field, inductances, flux linkages, and detent force, which are essential in modeling the motor. First, using a magnetic circuit model, the air-gap magnetic density is computed from stator magnetomotive force (MMF), flux barrier, and mover geometry. Second, the inductances, flux linkages, and detent force are analytically calculated using modified winding function and the air-gap magnetic density. Finally, a model has been established with the five-phase Park transformation and simulated. The calculations of detent force reveal that the end-effect force is the main component of the detent force. This is also proven by finite element analysis on the motor. The accuracy of the model is validated by comparing with the results obtained using semianalytical method (SAM) and measurements to analyze the motor's transient characteristics. In addition, the proposed method requires less computation time.
\end{abstract}

\section{Introduction}

Permanent magnet linear synchronous motors (PMLSM) have been developed for many years [1]. Compared with traditional rotary-to-linear electric actuators, these direct linear electric-mechanical energy conversion devices have no mechanical gears and transmission systems; hence, they possess higher dynamic performance and reliability [2]. Permanent magnet tubular linear motors (PMTLM) are a class of PMLSMs and are particularly attractive owing to zero attractive force between the stator and armature, high force density, excellent servo characteristics, and higher fault-tolerant performance [3]. PMTLM has been widely used in many linear motion fields, for example, transportation, manufacturing, health care, electromagnetic launch in space applications [4], ECO-pedal system [5], and so forth.

An accurate model is important in analyzing and controlling PMTLMs. In this regard, the calculation of air-gap magnetic field is critical in modelling the motor. This is because the air gap flux density distribution has a deep influence on the thrust ripples [6]. There are many methods to calculate the air-gap flux density distribution, for example, finite element method (FEM) [7], analytical method (AM) [8-11], or SAM [12]. FEM is an accurate numerical prediction method but it is time-consuming; thereby, it is not suitable for the simulation of a controlled machine [13]. AM can decrease the time consumed. It uses Laplace's and Poisson's equations to solve the scalar magnetic potential or the vector magnetic potential. However, the complicated boundary conditions increase the difficulty of the solving process [14]. SAM can balance the accuracy of the model and the time consumed. In [12], a 5phase PMTLM has been modelled with this method where the calculation of the magnetic field distribution has been done with FEM in advance. Consequently, modelling the motor is time-saving. However, once the motor power supply changes or faults arise, recalculation of the magnetic field distribution still needs using FEM. Hence, it is still timeconsuming. 


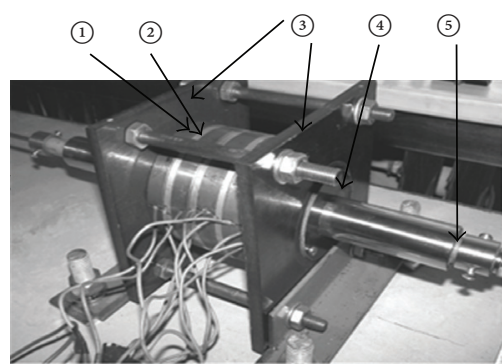

(1) Armature's segment

(2) Nonferromagnetic ring with stainless steel (3) Armature cover

(4) Linear sliding bearing

(5) Nonferromagnetic tube

(a)

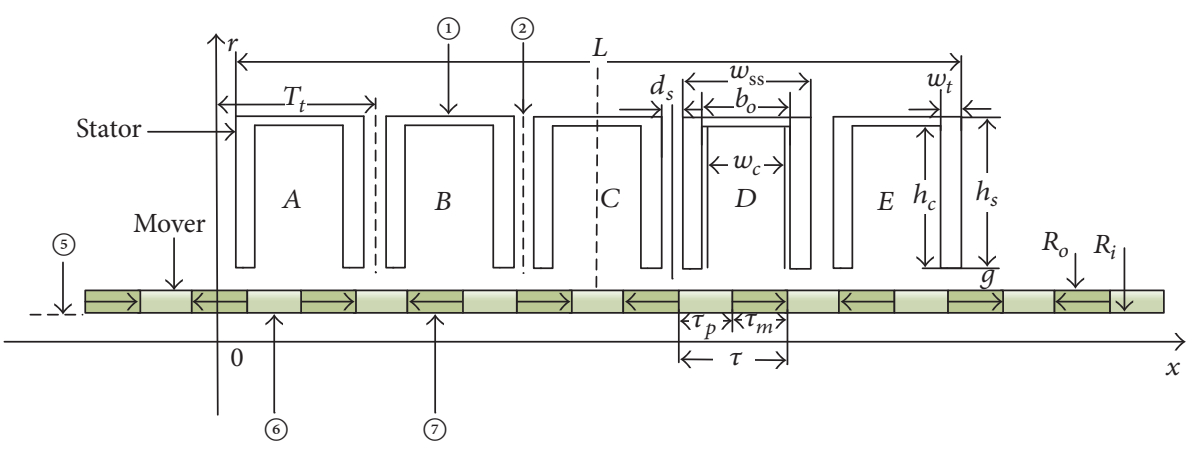

(1) Armature's segment

(2) Nonferromagnetic ring with stainless steel

(5) Nonferromagnetic tube
(6) Ferromagnetic ring

(7) Permanent magnet

(b)

Figure 1: Physical structure of PMTLM and the schematic outline of the halved motor cross section: (a) motor physical; (b) cross section of the motor.

TABle 1: Specifications of the PMTLM.

\begin{tabular}{llr}
\hline Symbol & Quantity & Value \\
\hline$w_{\mathrm{ss}}$ & Axial width of module & $18 \mathrm{~mm}$ \\
$b_{o}$ & Axial width of slot open & $12 \mathrm{~mm}$ \\
$w_{c}$ & Axial width of armature & $10 \mathrm{~mm}$ \\
$w_{t}$ & Axial thickness of module core (leg) & $3 \mathrm{~mm}$ \\
$T_{t}$ & Axial space of slot pitch & $21 \mathrm{~mm}$ \\
$\tau$ & Pole pitch & $15 \mathrm{~mm}$ \\
$h_{c}$ & Height of armature coil & $30 \mathrm{~mm}$ \\
$h_{s}$ & Height of module & $35 \mathrm{~mm}$ \\
$g$ & Air gap (mechanical clearance) & $1 \mathrm{~mm}$ \\
$d_{s}$ & Axial magnetic separation distance & $3 \mathrm{~mm}$ \\
$\tau_{p}$ & Axial ferromagnetic core width between PMs & $7 \mathrm{~mm}$ \\
$\tau_{m}$ & Axial PM width & $8 \mathrm{~mm}$ \\
$R_{o}$ & Outer radius of tubular reaction rail & $15 \mathrm{~mm}$ \\
$R_{i}$ & Inner radius of tubular reaction rail & $9 \mathrm{~mm}$ \\
$L$ & Axial width of stator & $102 \mathrm{~mm}$ \\
$N$ & Number of turns & $280 / \mathrm{slot}$ \\
\hline
\end{tabular}

Modified winding function approach is another analytical method which gives insight into the calculations of parameters without considering the complicated boundary conditions. It is a simple, fast modelling method for motors. This paper shows the detailed calculations of the parameters for a five-phase FSPMTLM, such as the detailed calculation of the detent force, which are not expressed distinctly in $[12,15,16]$. The model of the studied motor is established with MWFA and Park transformation theory, and the simulations results obtained by the mathematical model are compared with the ones obtained by SAM and measurements.

\section{Modified Winding Function Analysis}

2.1. Description of the Machine. Figure 1 shows the physical structure of a five-phase PMTLM and the schematic outline of the halved motor cross section. The stator is separated into five sections. Each section forms one phase and a magnetic separation of a nonferromagnetic ring made of stainless steel, which is used as a flux barrier. The mover is assembled from permanent magnets (PMs) and ferromagnetic rings; the PMs are characterized by axial magnetization and are situated alternately with the ferromagnetic rings. Table 1 gives details of the machine specifications.

2.2. Modified Winding Function on the Motor. MWFA was first proposed for solving air-gap eccentricity in rotary machines [17]. The modified winding function (MWF) was deduced from the MMF drops in a magnetic circuit between the stator and the rotor, which was obtained under the following assumptions: the iron in the stator and mover has infinite permeability; the magnetic saturation is neglected; the mover length is infinite so that the structure of the motor is symmetrical; there is no leakage flux in the shaft radial, $R_{i}$; and the magnetic permeability of the PMs is deemed as the magnetic permeability of air $\mu_{0}$. It is defined as follows

$$
M(\varphi, \theta)=n(\varphi, \theta)-\frac{\int_{0}^{2 \pi} n(\varphi, \theta) g^{-1}(\varphi, \theta) d \varphi}{2 \pi\left\langle g^{-1}(\varphi, \theta)\right\rangle}
$$

where $\varphi$ and $\theta$ represent the position of a stationary coil and angular position of the rotor with respect to stator, respectively. $M(\varphi, \theta), n(\varphi, \theta)$ and $g^{-1}(\varphi, \theta)$ represent the modified winding function, turns function, and air-gap function, respectively. The symbol $\langle\cdot\rangle$ represents the average value of “.”. If the rotor is not eccentric, (1) reduces to [17]

$$
M(\varphi, \theta)=n(\varphi, \theta)-\langle n\rangle,
$$

where $\langle n\rangle$ is the dc value of the turns function of the winding. 


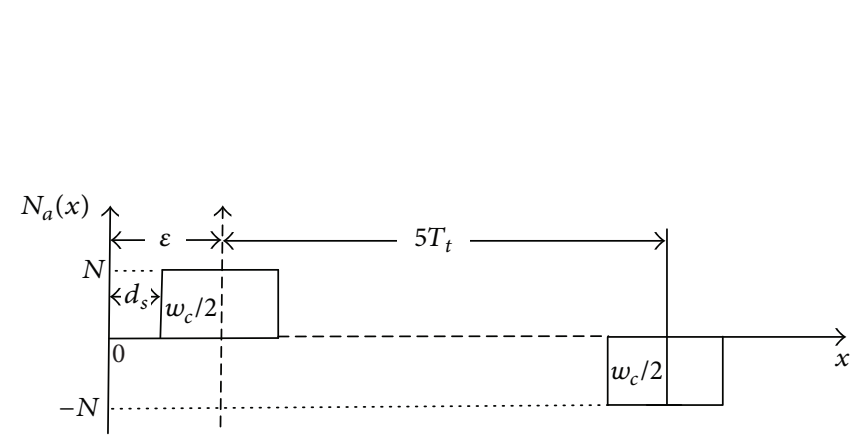

(a)

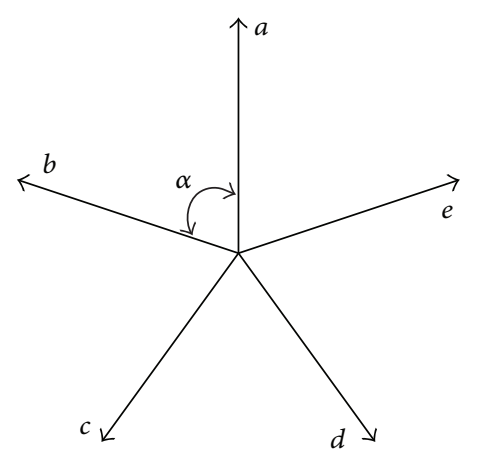

(b)

FIGURE 2: Winding function of phase " $a$ " and winding space distribution: (a) winding function; (b) spatial structure of windings.

Different from the rotary machines, the analysis of the modified winding function requires creating an appropriate coordinate system on the stator. As shown in Figure 1(b), the origin of coordinates is on the left schematic outline of the halved motor cross section, and the distance between origin and the center of the phase " $C$ " is 2.5 times axial space of slot pitch $T_{t}$. The pole pairs in the longitudinal section of the stator are 3.5, no matter whether the mover is run or not. Hence, the motor has a fractional-slot structure and the slot-perphase-per-pole (SPP) is equal to 2/7. Seen from Figure 1(b) and Table 1, along the shaft of the motor, the relation of the slot number $Q_{s}$, slot pitch $T_{t}$, pole pitch $\tau$, and pole pairs $p$ is written by

$$
Q_{s} T_{t}=2 p \tau
$$

Due to the influence of the fractional slot on the winding function distribution, the modified winding function of the five-phase FSPMTLM is defined as the product of winding function and the winding factor $y_{w}$ [18]. Similar to the rotary 5-phase PMSM [19], the longitudinal section of the five-phase FSPMTLM windings is assumed to be symmetrical. Figure 2 shows the winding function of the phase " $a$ " and the spatial structure of windings in five-phase FSPMTLM. The Fourier's expansion of the winding function of phase " $a$ " is calculated from

$$
\begin{aligned}
& N_{a}(x) \\
& =\frac{4 N}{p \pi} \sum_{k=1,3,5, \ldots} \frac{1}{k} \sin \left(\frac{w_{c} k \pi}{2 \tau}\right) \cos \left(\frac{k \pi}{\tau}(x-\varepsilon)\right) .
\end{aligned}
$$

In Figure 2(a), $N_{a}(x)$ is the winding function of phase " $a$," the letter " $\varepsilon$ " represents the distance between the origin, and the radial center line of phase " $a$ " and $N$ represents the stator turns number. In Figure $2(\mathrm{~b})$, " $\alpha$ ” is the winding space geometric angle of the adjacent phases. Because the stator structure is symmetrical, the plane is evenly divided into five blocks and each angle is equal to $2 \pi / 5$. Combining the all-order winding factor $y_{w k}$ ( $k$ is odd number and

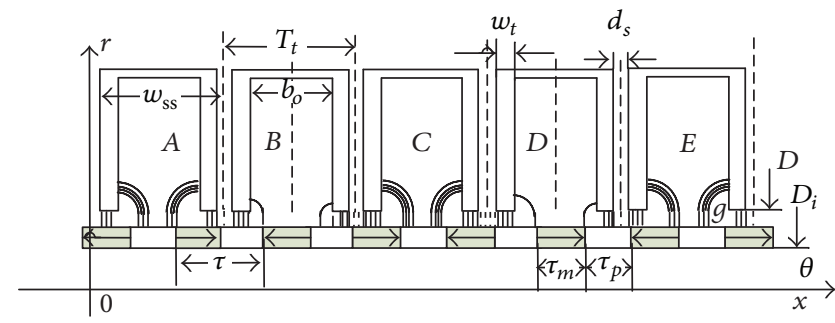

Figure 3: Flux paths due to the stator slot and mover saliency.

$k=1,3,5, \ldots)$ and (3) yields the all-phase modified winding function, $M_{i}(x)$ :

$$
\begin{aligned}
M_{i}(x)= & \frac{4 N}{p \pi} \sum_{k=1,3,5, \ldots} \frac{y_{w k}}{k} \sin \left(\frac{w_{c} k \pi}{2 \tau}\right) \\
& \cdot \cos \left(\frac{k \pi}{\tau}(x-\varepsilon-i \alpha)\right),
\end{aligned}
$$

where the subscript $i(i=0,1,2,3,4)$ represents the ordinal number of phase $a, b, c, d$, and $e$, respectively. For example, $M_{1}(x)$ shows the modified winding function of phase " $b$." The detailed calculation of (5) is as shown in Appendix A.

2.3. Air Gap Flux Density. The generation of air gap flux density is due to the current flowing in each phase. Hence, the flux density in phase " $a$ " and $B_{0}(x, \theta)$ is defined as the product of the modified winding function $M_{0}(x)$ and the inverse air gap function $g^{-1}(x, \theta)[20]$ :

$$
B_{0}(x, \theta)=\mu_{0} g^{-1}(x, \theta) M_{0}(x) i_{a},
$$

where $\theta$ is the distance which the mover has covered from the origin of the stator coordinates and $i_{a}$ is the current of phase " $a$."

Calculation of the inverse air gap function $g^{-1}(x, \theta)$ requires modeling the flux paths through the air gap regions with straight lines and circular arc segments [20]. The flux paths due to the mover saliency are shown in Figure 3. The inverse air gap function $g^{-1}(x, \theta)$ is obtained by the unslotted 


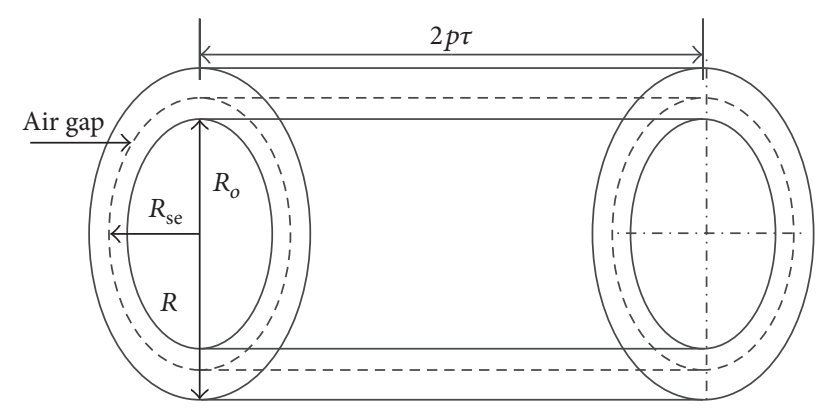

FIgURE 4: The schematic diagram of computational volume in the air gap.

air-gap flux density [21] and the relative air-gap permeance [22]. The calculation of $g^{-1}(x, \theta)$ in the Fourier series form is

$$
g^{-1}(x, \theta)=\sum_{n=0}^{\infty} G_{n} \cos \left(\frac{n \pi}{\tau}(x-\theta-\varepsilon)\right),
$$

where the expression of the coefficient $G_{n}$ is

$$
\begin{aligned}
G_{n}= & \frac{4}{2.5 T_{t}} \int_{\theta+\varepsilon}^{T_{t}+\theta+\varepsilon} g^{-1}(x, \theta) \cos \left(\frac{n \pi}{\tau}(x-\theta-\varepsilon)\right) d x \\
& +\frac{2}{2.5 T_{t}} \int_{\theta}^{\theta+\varepsilon} g^{-1}(x, \theta) \cos \left(\frac{n \pi}{\tau}(x-\theta-\varepsilon)\right) d x .
\end{aligned}
$$

The detailed computations of the inverse air-gap function $g^{-1}(x, \theta)$ are shown in Appendix B.

2.4. Calculations of Inductances and Permanent Magnet Flux Linkages. In terms of the modified winding function theory, the inductances and the permanent magnet flux linkages are derived from the air-gap function and the modified winding functions. Both are computed for the volume of the air-gap section of the motor with the effective air-gap radius $R_{\text {se }}$ [23], as is depicted in Figure 4.

In Figure $4, R_{o}$ and $R$ are the outer radius of tubular reaction rail and the radius of the stator tooth, respectively (see Section 2.1). $R_{\text {se }}$ is the effective air-gap computational radius and the length of the computational volume is $2 \mathrm{p} \tau$ (see Section 2.2).

The self and mutual inductances are computed in the computational volume, as shown by $[17,23]$ :

$$
\begin{gathered}
L_{i i}(\theta)=2 \pi R_{\mathrm{se}} \mu_{0} \int_{0}^{2 p \tau} M_{i}^{2}(x) g^{-1}(x, \theta) d x \\
(i=0,1,2,3,4), \\
L_{i j}(\theta)=2 \pi R_{\mathrm{se}} \mu_{0} \int_{0}^{2 p \tau} M_{i}(x) M_{j}(x) g^{-1}(x, \theta) d x \\
(i \neq j, i, j=0,1,2,3,4),
\end{gathered}
$$

where $L_{i i}(\theta)$ and $L_{i j}(\theta)$ are the self-inductances and mutual inductances, which are the function of mover position $\theta$; $M_{i}(\theta)$ and $M_{j}(\theta)$ are the modified winding functions of the $i$ th phase and the $j$ th phase, respectively.
The permanent magnet flux linkages are derived from the air-gap flux density produced by permanent magnets and the modified winding functions, as computed by

$$
\psi_{m i}(\theta)=2 \pi \mu_{0} R_{\text {se }} \int_{0}^{2 p \tau} M_{i}(x) B_{g}(x, \theta) d x,
$$

where $B_{g}(x, \theta)$ represents the air-gap flux density, which is the product of PM flux density $B_{\mathrm{pm}}(x, \theta)$ and relative air gap permeance $\lambda_{\mathrm{ag}}(x, \theta)[22]$.

The detailed calculations of the effective air-gap computational radius $R_{\text {se }}$ and the air-gap flux density $B_{g}(x, \theta)$ are shown in Appendix C.

\section{Mathematical Model}

3.1. Basic Model of the PMLMs. The stator voltage equations and mechanical thrust equations compose the mathematical model of PMLMs [24]:

$$
V_{s}=R_{s} I_{s}+\frac{d \psi_{s}}{d t}
$$

where $V_{s}, R_{s}$, and $I_{s}$ represent the stator voltage, the stator resistance, and the stator current, respectively. $\psi_{s}$ represents the air-gap flux linkages produced by the permanent magnet and the stator currents. It can be calculated from the following formulae:

$$
\psi_{s}=\psi_{m}+L_{s} I_{s}
$$

where $\psi_{m}$ is the flux linkages produced by PMs; $L_{s}$ represents the inductances matrix including self- and mutual inductances matrix, as computed by (9):

$$
F_{e}=m \frac{d v}{d t}+D v+F_{l}+F_{\text {detent }}
$$

where $F_{e}$ is the electromagnetic thrust force, $m$ is the total mass on the mover, $D$ is the dynamical friction coefficient, $v$ is the mover velocity, $F_{l}$ is the load force, and $F_{\text {detent }}$ is the detent force including the end-effect force $F_{\text {end }}$ and slot-effect force $F_{\text {slot }}$.

3.2. Calculations of the Detent Force. The detent force is the interaction force between the mover magnets and stator slots without the stator currents flowing [25]. Due to the opening stator slots and the bilateral ends of the stator, the detent force is the sum of the end-effect force $F_{\text {end }}$ and slot-effect force $F_{\text {slot }}$ :

$$
F_{\text {detent }}=F_{\text {slot }}+F_{\text {end }} \text {. }
$$

Using the Virtual Work Method (VWM), $F_{\text {end }}$ and sloteffect force $F_{\text {slot }}$ are obtained by

$$
F=-\frac{\partial W}{\partial \theta}
$$

where $W$ is the air gap magnetic field energy produced by the computational volume $V$ of each section, as is given by [26]

$$
W=\frac{1}{2 \mu_{0}} \int_{V} B_{g}^{2}(x, \theta) d V .
$$




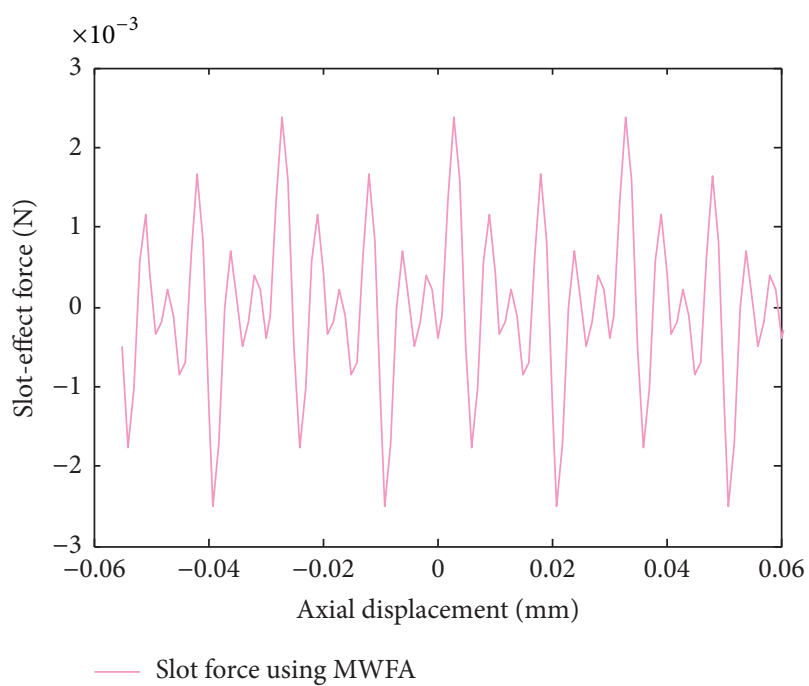

(a)

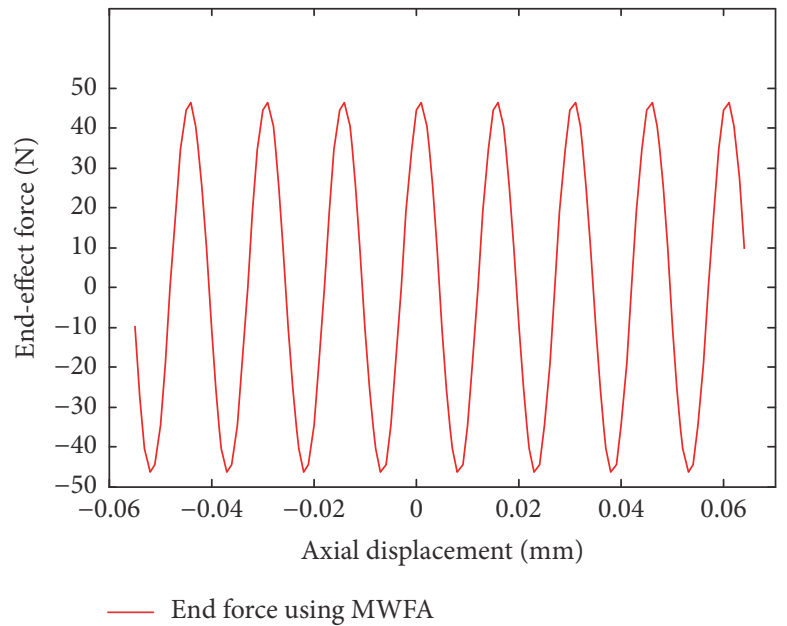

(b)

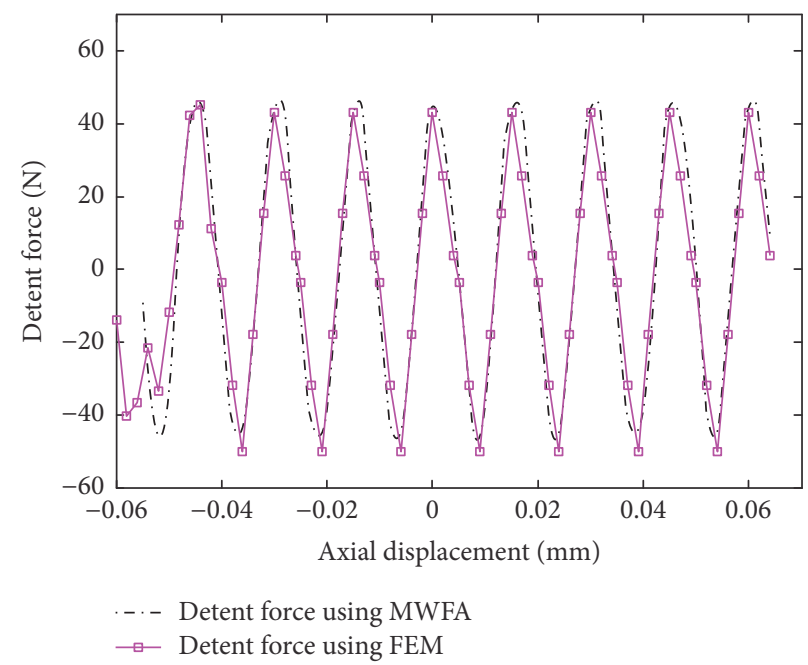

(c)

FIGURE 5: Calculations of slot force, end force and detent force distribution versus mover position.

The detailed calculations of the detent force obtained by using the MWFA are shown in Appendix D.

Figure 5 shows the calculation results of the slot-effect force, the end-effect force, and the detent force. In Figures 5 (a) and 5(b), the results of the slot-effect force and the endeffect force are obtained using MWFA, while Figure 5(c) shows the calculation results using MWFA and FEM. Figure 6 establishes the finite element analysis model of the studied motor in a cylindrical coordinate system. The fractionalslot structure is adopted in the model and also the flux line distribution of the five-phase PMTLM is shown in Figure 6.

Seen from Figures 5(a)-5(c), the following conclusions are obtained: (1) since the amplitude of the end-effect force is $46.3911 \mathrm{~N}$ yet the slot-effect force is $2.5 \mathrm{mN}$, the end-effect force is the largest component of detent force. That is to say, the slot-effect force has been weakened in such a motor; (2) the results using MWFA to compute the detent force are in accordance with results using FEM. Hence, the accuracy of the detent force using the proposed method is validated by using FEM.

3.3. Mathematical Model of the Five-Phase FSPMTLM. As seen from Section 3.1, the basic mathematical model of PMLMs is a multivariable system with strong coupling. It is hard to analyze the motor characteristics and control the motor. The motor system is decoupled by applying Park transformation theory (PTT) which has been widely applied in motor vector control (VC) [27]. Using PTT to model the studied motor can ease the analysis of the transient characteristics. In [28], using a Park transformation matrix $T(\theta)$ to model a five-phase permanent magnet synchronous Motor (PMSM) was reported. The studied motor has the same five-phase power supply; however, it has the structure of the linear motor which is different from the five-phase PMSM. When the other harmonic components are ignored, the Park transformation matrix becomes 


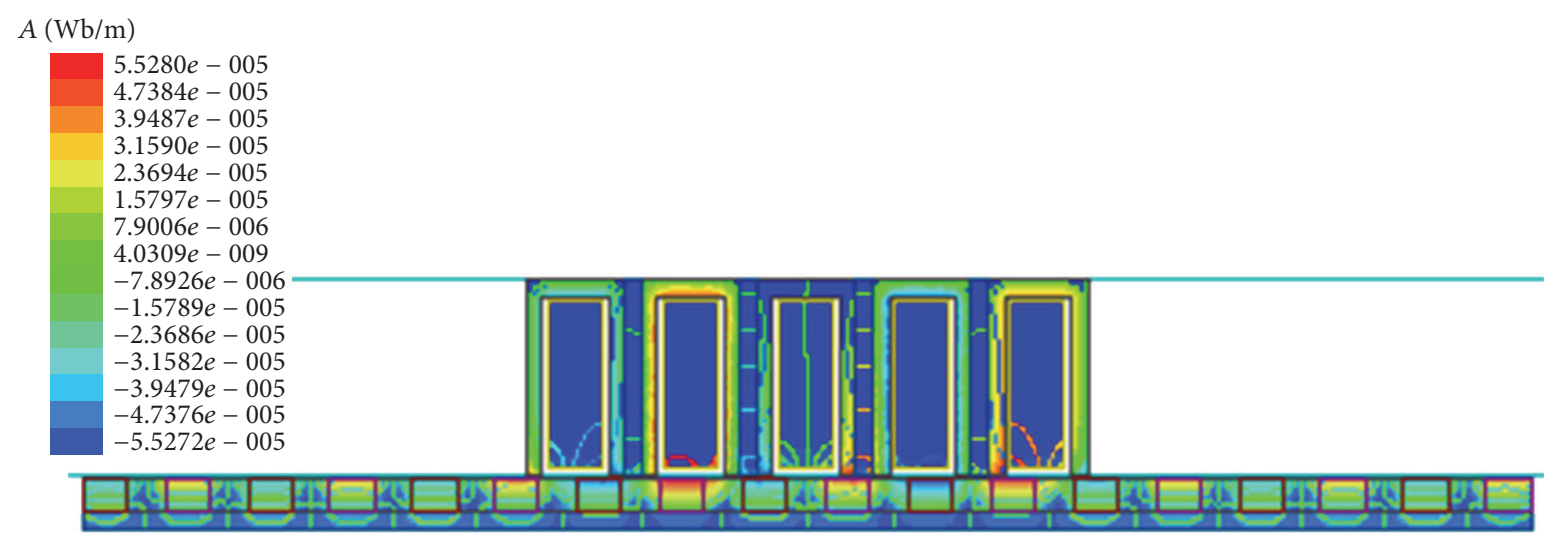

FIGURE 6: Five-phase FSPMTLM model using finite element method.

$$
T(\theta)=\frac{2}{5}\left[\begin{array}{ccccc}
\cos \left(\frac{\pi}{\tau} \theta\right) & \cos \left(\frac{\pi}{\tau} \theta-\alpha\right) & \cos \left(\frac{\pi}{\tau} \theta-2 \alpha\right) & \cos \left(\frac{\pi}{\tau} \theta+2 \alpha\right) & \cos \left(\frac{\pi}{\tau} \theta+\alpha\right) \\
-\sin \left(\frac{\pi}{\tau} \theta\right) & -\sin \left(\frac{\pi}{\tau} \theta-\alpha\right) & -\sin \left(\frac{\pi}{\tau} \theta-2 \alpha\right) & -\sin \left(\frac{\pi}{\tau} \theta+2 \alpha\right) & -\sin \left(\frac{\pi}{\tau} \theta+\alpha\right) \\
\cos \left(\frac{\pi}{\tau} \theta\right) & \cos \left(\frac{\pi}{\tau} \theta+2 \alpha\right) & \cos \left(\frac{\pi}{\tau} \theta-\alpha\right) & \cos \left(\frac{\pi}{\tau} \theta+\alpha\right) & \cos \left(\frac{\pi}{\tau} \theta-2 \alpha\right) \\
-\sin \left(\frac{\pi}{\tau} \theta\right) & -\sin \left(\frac{\pi}{\tau} \theta+2 \alpha\right) & -\sin \left(\frac{\pi}{\tau} \theta-\alpha\right) & -\sin \left(\frac{\pi}{\tau} \theta+\alpha\right) & -\sin \left(\frac{\pi}{\tau} \theta-2 \alpha\right) \\
\frac{1}{\sqrt{2}} & \frac{1}{\sqrt{2}} & \frac{1}{\sqrt{2}} & \frac{1}{\sqrt{2}} & \frac{1}{\sqrt{2}}
\end{array}\right],
$$

where $\theta$ is the position of the mover, $\alpha$ is the winding space geometric angles of adjacent phases, and $\alpha=0.4 \pi$ (see Section 2.2).

Using (17) to transform (11)-(13), the mathematical model with the Park transformation form is written as

$$
\begin{aligned}
V_{d} & =R_{s} i_{d}-\frac{\pi}{\tau} \nu L_{q} i_{q}+L_{d} \frac{d i_{d}}{d t}, \\
V_{q} & =R_{s} i_{q}+\frac{\pi}{\tau} \nu\left(L_{d} i_{d}+\psi_{m}^{\prime}\right)+L_{q} \frac{d i_{q}}{d t}, \\
F_{e} & =\frac{5}{2} \frac{\pi}{\tau} p\left[\psi_{m}^{\prime} i_{q}+\left(L_{d}-L_{q}\right) i_{d} i_{q}\right], \\
m \frac{d \nu}{d t} & =D \nu+F_{l}+F_{\text {detent }}-F_{e},
\end{aligned}
$$

where $V_{d}$ and $V_{q}$ are the direct-axis and quadrature-axis voltage; $R_{s}$ is the stator resistance; $i_{d}$ and $i_{q}$ are direct-axis and quadrature-axis currents, $v$ is the mover velocity; $L_{d}$ and $L_{q}$ are the direct-axis and quadrature-axis inductances. $\psi_{m}^{\prime}$ is the amplitude of the PM flux linkage; the remaining parameters are the same as (13); and the detailed calculations of $V_{d}, V_{q}$, $i_{d}, i_{q}$, and $\psi_{m}^{\prime}$ are shown in Appendix E.

\section{The Simulation Analysis of the Motor Transients}

In papers [12, 15], a model using semianalytical method was validated by the measurements results of the transient characteristics. Likewise, in order to verify the accuracy of the proposed model, model (18) has been established on the Matlab/Simulink platform where it has been simulated to analyze the transient characteristics of the studied motor in this section. In addition to the basic motor parameters: the stator resistance $R_{s}\left(R_{s}=5 \Omega\right)$; the friction coefficient $D(D=$ $3000)$; the nominal value of the winding current $I$ ( $I=8 \mathrm{~A})$; and the mass of the mover $m(m=9.2 \mathrm{~kg})$, which were shown in $[12,15]$, and the following parameters of the motor model $L_{d}, L_{q}, \psi_{m}^{\prime}$ and $F_{\text {detent }}$ need to be calculated by using MWFA. The computed results are as follows: $L_{d}=3.6 \mathrm{mH} ; L_{q}=$ $6.8 \mathrm{mH} ; \psi_{m}^{\prime}=0.2261 \mathrm{~Wb}$, and the detent force $F_{\text {detent }}$ has been shown in Appendix D. Figure 7 shows the proposed mathematical model established on the Matlab/Simulink platform.

In Figure 7, the model established on the Matlab/Simulink platform is composed by the current excitation, the current balance subsystem, and mechanical balance subsystem. The current excitation implemented using the PWM converter is the same as the ones in $[12,15]$, which are the five-phase symmetric cosine current sources, $i_{a}, i_{b}, i_{c}, i_{d}$, and $i_{e}$, while the mover velocity $v$ is derived from the frequencies of the current sources, as shown by

$$
f=\frac{v}{2 \tau} \text {. }
$$

$F_{\text {load }}$ represents the load force on the mover, Theta represents position along the mover movements direction, and $k$ is the amplification factor which can magnify the mover position 1000 times. The corresponding unit of the position is 


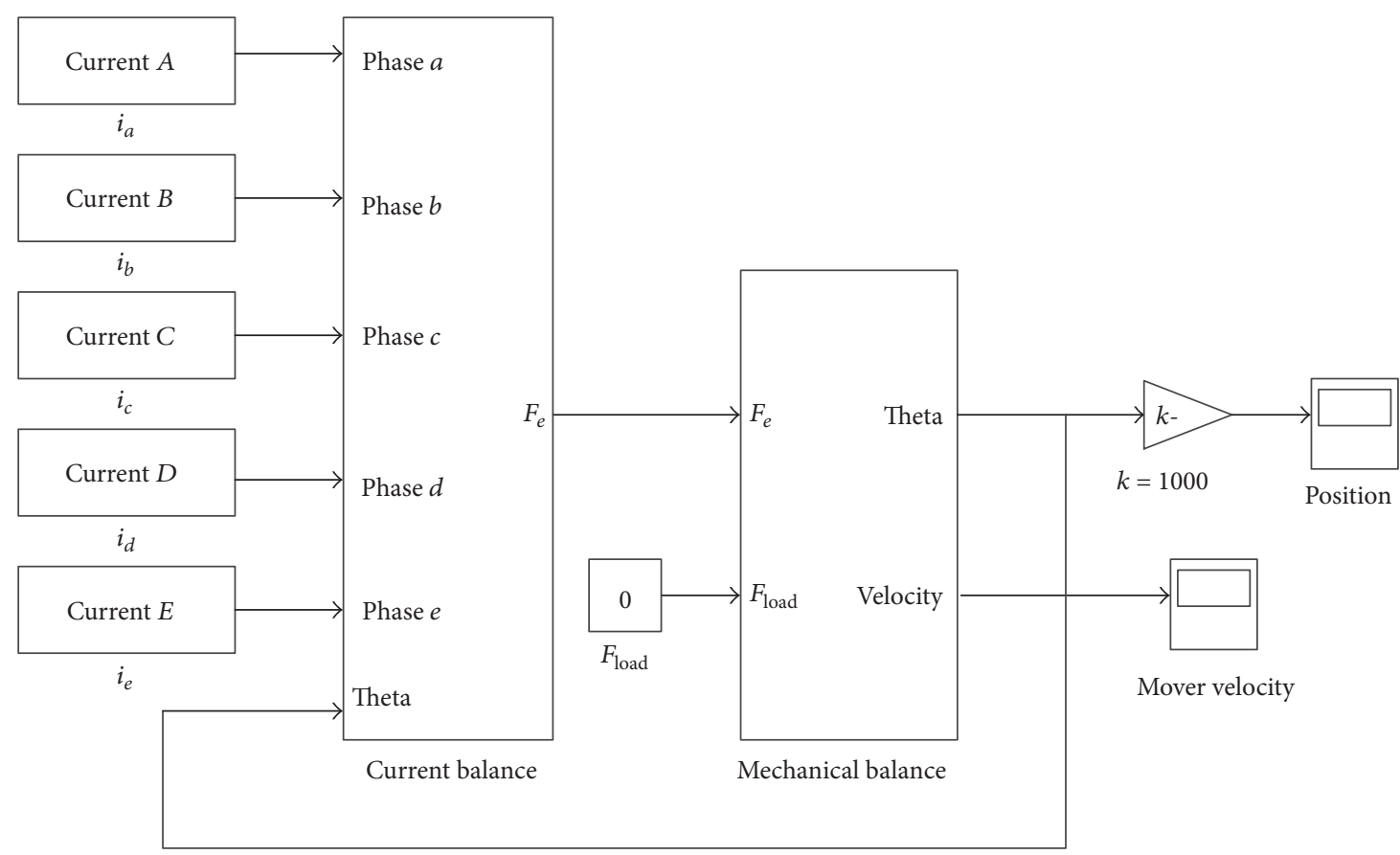

FIGURE 7: Establishment of the studied motor model on Matlab/Simulink platform.

in millimeters. The current balance subsystem and mechanical balance subsystem are shown in Figures 8(a) and 8(b).

In Figure 8(a), the current subsystem is derived from the 3 rd equation of (18). In the DQ transformation module shown in this figure, which is established from the Park transformation matrix, $T(\theta)$ is given in (17). $F_{m}$ is the amplitude of the PM flux linkages, which represents $\psi_{m}^{\prime}$ in (18). In Figure 8(b), the mechanical subsystem is derived from the 4 th equation of (18).

The simulations using the proposed model to analyze the motor transients are carried out. This is done for the three cases given in [12]. The results are then compared with results from SAM and measurements. The three cases are as follows.

Case 1. The velocity of the mover is set to $18 \mathrm{~mm} / \mathrm{s}$ and there is no load. The simulation results of the mover position (versus time) and the velocity of the mover (versus time) are shown in Figures 9 and 10.

Figure 9 shows the simulation results using the proposed model have a close agreement with the results from SAM and measurements in [12]. Figure 10 shows slight oscillations of the mover velocity around the set $18 \mathrm{~mm} / \mathrm{s}$. However, the position increases linearly with time without any oscillations.

Case 2. The velocity of the mover is set to $1 \mathrm{~m} / \mathrm{s}$ and no load is installed on the mover. The simulation results of the mover position (versus time) and the velocity (versus time) are shown in Figures 11 and 12.

Figure 11 shows the simulation results using the proposed model are almost identical to the results from measurements and SAM. The results show some variances at the beginning of the mover running; however, these die out after $0.04 \mathrm{~s}$. Figure 12 shows the mover velocity around the setting of
$1 \mathrm{~m} / \mathrm{s}$. The slight oscillations of the mover velocity have small variations after $0.04 \mathrm{~s}$. Hence, these results are consistent.

Case 3. An additional mass $m_{\Delta}\left(m_{\Delta}=19.2 \mathrm{~kg}\right)$ was linked to the mover. The average velocity of the mover has been assumed $50 \mathrm{~mm} / \mathrm{s}$. The results of the position (versus time) and velocity (versus time) are shown in Figures 13 and 14, respectively.

The additional mass brings out more ripples in the mover position than in Cases 1 and 2. The two causes of the ripples are the resistance offered by the higher inertia to the motor and that by the detent force. In Figure 13, the variation trends between the simulation results using the proposed model and the ones obtained by using SAM are similar, although there are some slight differences. Also, it is noted that the higher velocity changes seen in Figure 14 indicate the presence of thrust ripples.

\section{Conclusions}

In this paper, a method based on modified winding function theory was applied to model a five-phase fractional-slot permanent magnet tubular linear motor. The proposed method has provided the detailed computational expressions of the air-gap flux density, the inductance, flux linkages, and the detent force. Due to the fact that it has a property of fast modeling no matter whether the motor is healthy or not, it can make up for the time-consuming remodeling of the motor using finite element analysis and semianalytical method when the faults arise or supply power changes. The analytical results showed that the slot-effect force had been greatly reduced by this structural design, and the main component 


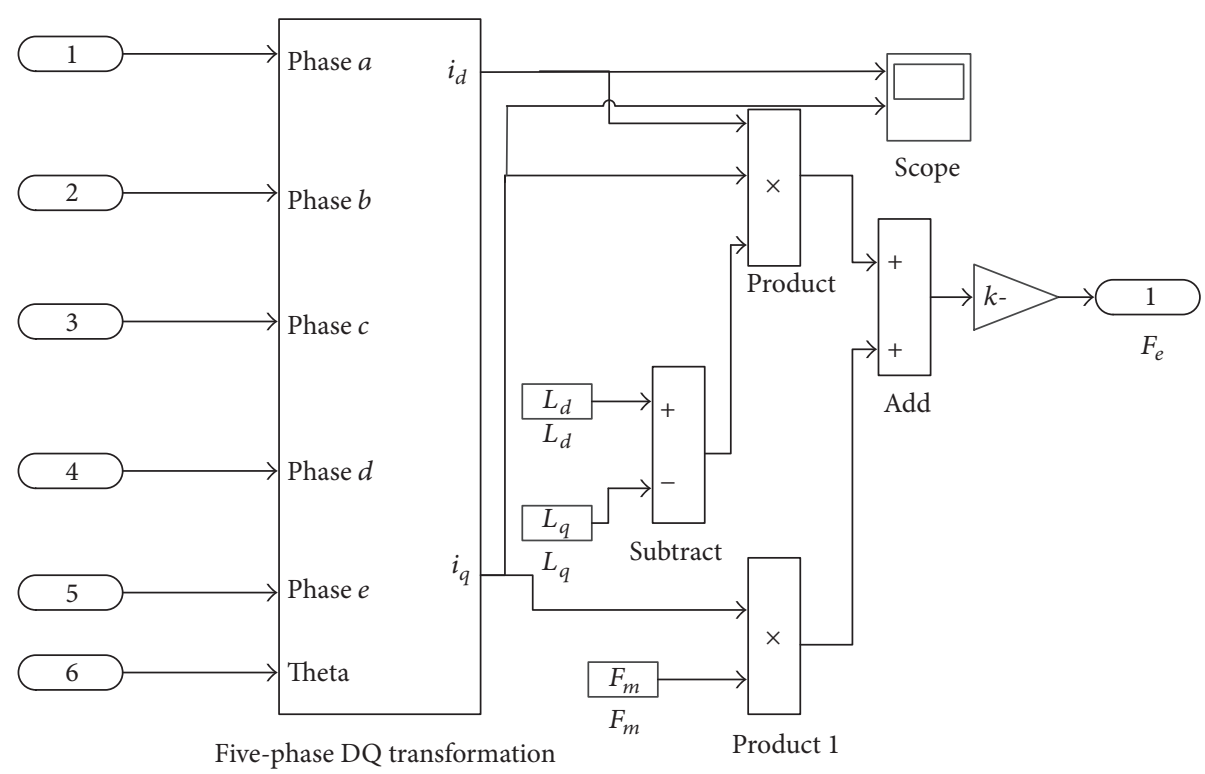

(a)

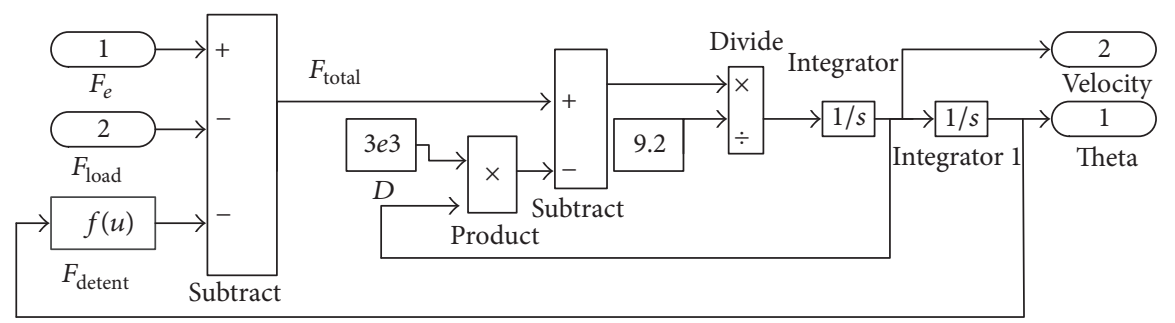

(b)

FIGURE 8: Subsystem of the proposed model: (a) current balance subsystem, (b) mechanical balance subsystem.

of the detent force is the end-effect force. This is as had been demonstrated by using the finite element model. In this proposed approach, a model with five-phase Park transformation had been established and simulated. The simulation results for transients on the motor were analyzed and were close to those of semianalytical method and measurements. In this way, the accuracy of the model using MWFA was validated.

\section{Appendix}

\section{A. Calculations of the Winding Function, Winding Factor, and Modified Winding Function}

A.1. Winding Function Computation. As shown in Figure 2(a), on moving the coordinate system by a distance " $\varepsilon$ " along the $x$-axis, the winding function of phase " $a$ " becomes an even function. Using Fourier's expansion method, the winding function of phase " $a$ " in form of Fourier expansion is written by

$$
N_{a}(x)=\sum_{k=1,3,5, \ldots} a_{k} \cos \left(\frac{2 p k \pi}{5 T_{t}}(x-\varepsilon)\right),
$$

where $N_{a}(x)$ represents the winding function of phase " $a$ "; $k$ is the order of the coefficients of the Fourier's expansion;
$T_{t}$ and $w_{c}$ represent the axial space of slot pitch and the axial width of armature (see Figure 1(b)), respectively; $p$ represents the pole pairs; " $\varepsilon$ " is the distance between the former origin and the new origin (see Figure 2(a)); " $a_{k}$ " is the $k$ th Fourier's expansion coefficient, as calculated by

$$
\begin{aligned}
a_{k} & =\frac{2}{5 T_{t}}\left(\int_{0}^{w_{c} / 2} N \cos \left(\frac{2 p k \pi}{5 T_{t}} x\right) d x\right. \\
& \left.+\int_{5 T_{t}-w_{c} / 2}^{5 T_{t}}-N \cos \left(\frac{2 p k \pi}{5 T_{t}} x\right) d x\right)=\frac{4 N}{p k \pi} \\
& \cdot \sin \left(\frac{w_{c} p k \pi}{5 T_{t}}\right) .
\end{aligned}
$$

Plugging (A.2) into (A.1) and combining with (3), the winding function of phase " $a$ " in form of Fourier expansion is given by

$$
\begin{aligned}
& N_{a}(x)=\sum_{k=1,3,5, \ldots} a_{k} \cos \left(\frac{2 p k \pi}{5 T_{t}}(x-\varepsilon)\right) \\
& =\frac{4 N}{p \pi} \sum_{k=1,3,5, \ldots} \frac{1}{k} \sin \left(\frac{w_{c} k \pi}{2 \tau}\right) \cos \left(\frac{k \pi}{\tau}(x-\varepsilon)\right) .
\end{aligned}
$$

Then, the expression (4) is obtained. 


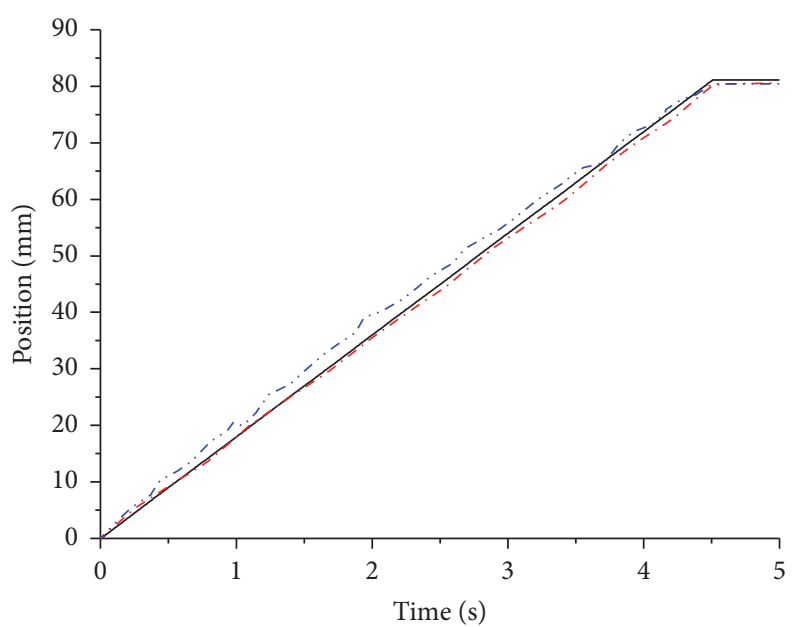

- Simulation results using the proposed model

-. - Simulation results of the model using SAM, [12]

... Measurement results, [12]

FIGURE 9: Transient characteristic of the mover position under noload for $v=18 \mathrm{~mm} / \mathrm{s}$.

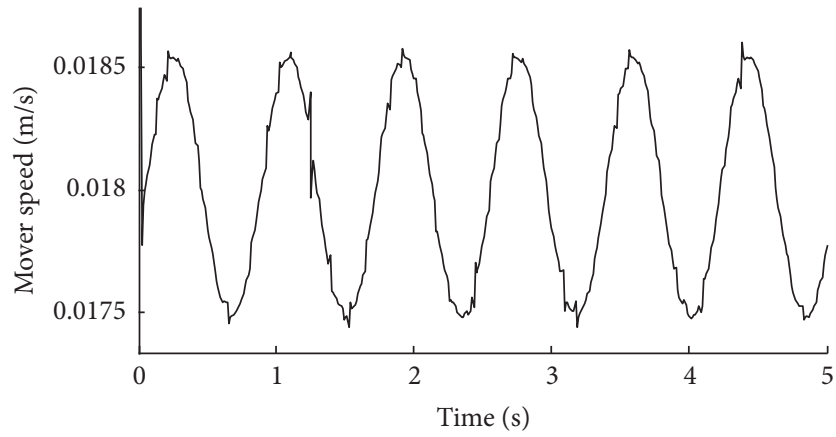

FIGURE 10: Simulation results of the mover velocity under no-load for $\nu=18 \mathrm{~mm} / \mathrm{s}$.

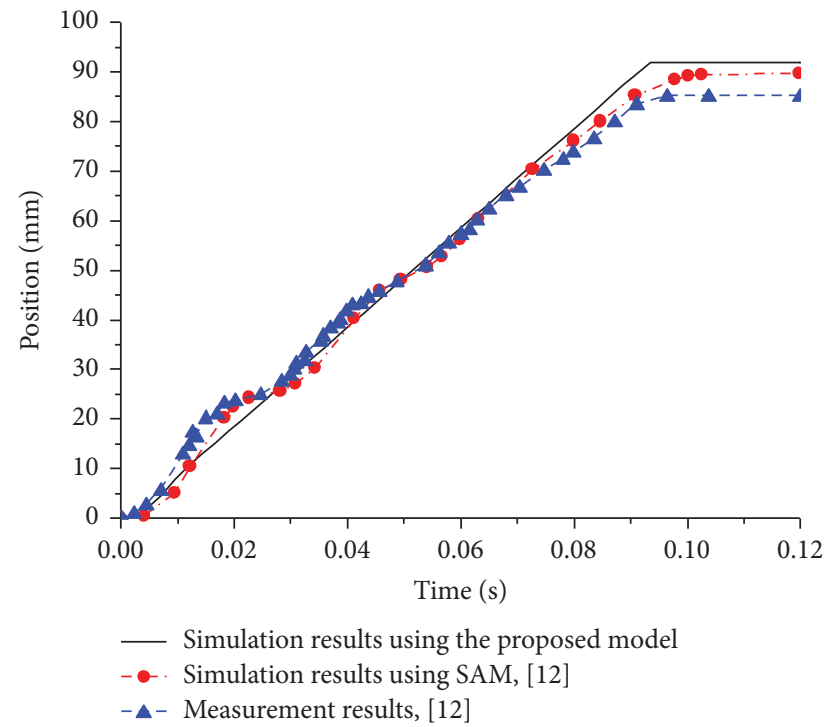

FIGURE 11: Transient characteristics of the mover position under noload for $v=1 \mathrm{~m} / \mathrm{s}$.

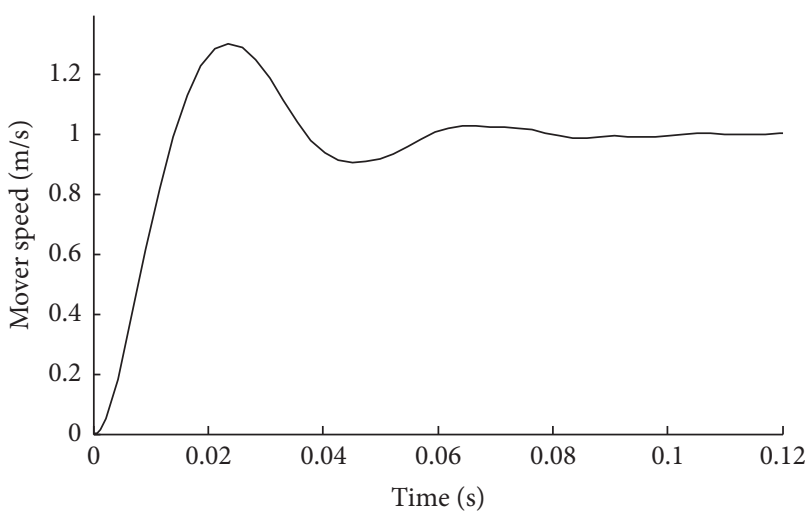

FIGURE 12: Simulation results of the mover velocity under no-load for $\nu=1 \mathrm{~m} / \mathrm{s}$.

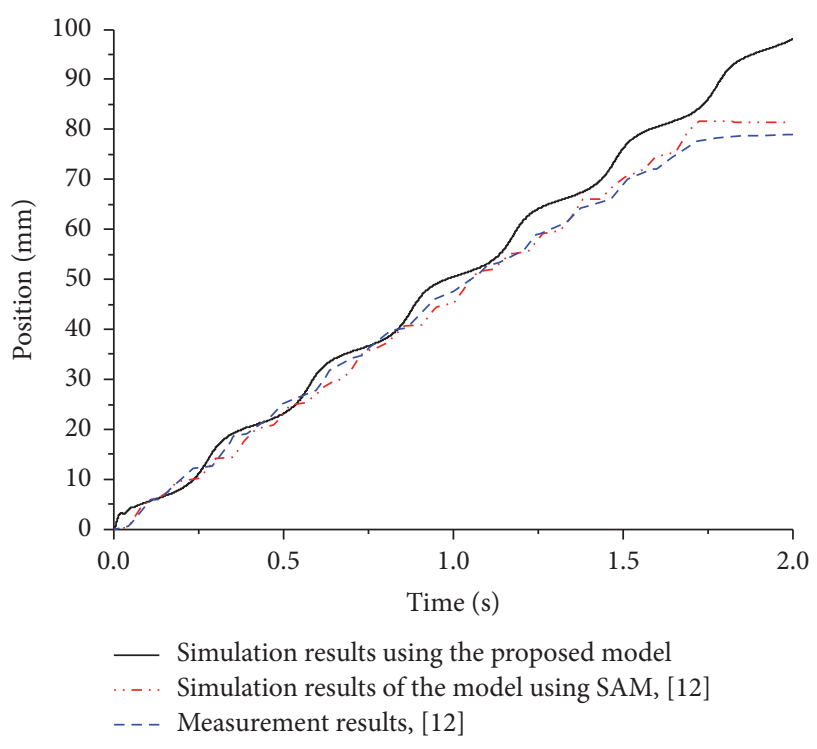

FIGURE 13: Transient characteristic of the mover position under an additional inertial load with the mass $m_{\Delta}=19.2 \mathrm{~kg}$ for $\nu=50 \mathrm{~mm} / \mathrm{s}$.

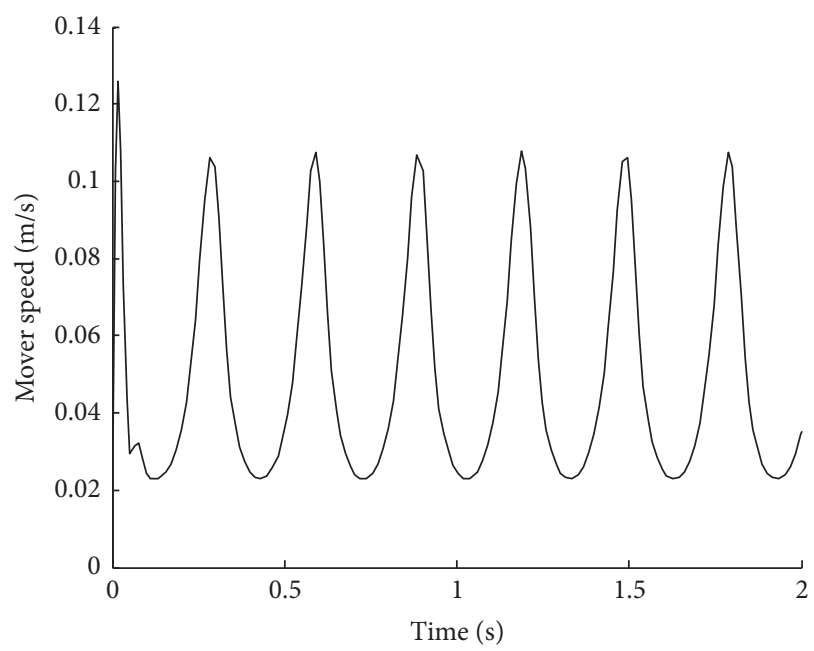

FIGURE 14: Simulation results of the mover velocity under an additional inertial load with the mass $m_{\Delta}=19.2 \mathrm{~kg}$ for $\nu=50 \mathrm{~mm} / \mathrm{s}$. 


\section{A.2. Winding Factor Computations}

Definition of $d_{s}, y_{w k}, y_{y k}$, and $y_{d k} . d_{s}$ shown in Figure 2(a) is the axial magnetic separation distance between two adjacent phase; $y_{w k}, y_{y k}$, and $y_{d k}$ represent the $k$ th winding factor, $k$ th pitch factor, and $k$ th winding distribution factor, respectively. In the light of the papers $[29,30], y_{w k}$ is the product of $y_{y k}$ and $y_{d k}$ :

$$
y_{w k}=y_{y k} \cdot y_{d k}
$$

where

$$
\begin{aligned}
& y_{y k}=\sin \left(\frac{k\left(T_{t}-d_{s}\right)}{\tau} \cdot \frac{\pi}{2}\right), \\
& y_{d k}=\frac{\sin \left(k \theta_{d} / 2\right)}{\left(N \sin \left(k \theta_{d} / 2 N\right)\right)},
\end{aligned}
$$

where

$$
\theta_{d}=\frac{\pi}{\tau} \operatorname{abs}\left(\tau-\left(T_{t}-d_{s}\right)\right)
$$

A.3. All-Phase Modified Winding Function Computations. All-phase modified winding function $M_{i}(x)$ is the product of winding function and winding factor. Therefore, combining the spatial structure of windings in Figure 2(b) with all-order winding factor $y_{w k}$ yields (3):

$$
\begin{aligned}
& M_{i}(x)=N_{i}(x) \cdot y_{w k}=\frac{4 N}{p \pi} \\
& . \sum_{k=1,3,5, \ldots} \frac{y_{w k}}{k} \sin \left(\frac{w_{c} k \pi}{2 \tau}\right) \cos \left(\frac{k \pi}{\tau}(x-\varepsilon-i \alpha)\right) .
\end{aligned}
$$

Then, the expression (5) is obtained.

\section{B. Analysis of Inverse Air Gap Function}

The air gap magnetic field is the product of the PM field with unslotted stator and the relative air gap permeance [22]. Paper [21] has shown the expression of unslotted PM field $B_{g}$ :

$$
B_{g}=\frac{H_{c} \tau_{m}}{2} \frac{\mu_{0}}{g^{\prime}}=\frac{H_{c} \tau_{m}}{2} \frac{\mu_{0}}{g+\tau_{m} \tau_{p} D / \mu_{r}\left(D^{2}-D_{i}^{2}\right)},
$$

where $H_{c}=950 \mathrm{kA} / \mathrm{m}, \mu_{r}=1.048, D$ is the diameter of the inner stator core and $D=2\left(R_{o}+g\right), D_{i}$ is the diameter of the inner tubular reaction rail and $D_{i}=2 R_{i}, \tau_{m}$ is the axial PM width, and $\tau_{p}$ is the axial ferromagnetic core width between PMs. We can suppose $\tau_{p}$ is equal to $\tau_{m}$ (in Table $1, \tau_{m}=8 \mathrm{~mm}$ and $\tau_{p}=7 \mathrm{~mm}$ ); thereafter, along the $x$-axis, the air gap function $g(x, \theta)$ in one pitch $T_{t}$ is

$$
\begin{aligned}
& |x-\theta-\varepsilon| \leq \frac{\tau_{p}}{2} \\
& \frac{\tau_{p}}{2}<|x-\theta-\varepsilon| \leq \frac{w_{\mathrm{ss}}}{2} \\
& \frac{w_{\mathrm{ss}}}{2}<|x-\theta-\varepsilon| \leq \frac{T_{t}+d_{s}}{2} \\
& \frac{T_{t}+d_{s}}{2}<|x-\theta-\varepsilon| \leq \frac{T_{t}+d_{s}}{2}+w_{t} \\
& \frac{T_{t}+d_{s}}{2}+w_{t}<|x-\theta-\varepsilon| \leq \frac{\tau_{p}}{2}+\tau \\
& \frac{\tau_{p}}{2}+\tau<|x-\theta-\varepsilon| \leq T_{t} .
\end{aligned}
$$

Combining (3), the above two formulas (B.3) and (B.4) are written by (5) and (6), respectively.

\section{Definition of the Relative Air-Gap Permeance $\lambda_{\mathrm{ag}}(x, \theta)$, the Air-Gap Flux Density $B_{g}(x, \theta)$, and Effective Air-Gap Computational Radius $R_{\text {se }}$}

In light of the paper [22], the relative air-gap permeance $\lambda_{\mathrm{ag}}(x, \theta)$ is computed by

$$
\lambda_{\mathrm{ag}}(x, \theta)=g^{\prime} \cdot g^{-1}(x, \theta) .
$$

Because air gap $g$ is small (see Table $1, g=1 \mathrm{~mm}$ ), the air-gap flux density $B_{g}(x, \theta)$ is deduced by the product of 
$\lambda_{\mathrm{ag}}(x, \theta)$ and flux density produced by PMs with unslotted stator $B_{\text {pm-slotless }}(x, \theta)$,

$$
B_{g}(x, \theta)=\lambda_{\text {ag }}(x, \theta) B_{\text {pm-slotless }}(x, \theta),
$$

where $B_{\text {pm-slotless }}(x, \theta)$ can be expanded by Fourier series along the shaft of the motor:

$$
\begin{aligned}
B_{\text {pm-slotless }}(x, \theta)= & \frac{4 B_{g}}{\pi} \sum_{n=1,3,5, \ldots} \frac{1}{n} \sin \left(\frac{n \pi}{2}\right) \\
& \cdot \cos \left(\frac{n \pi \tau_{m}}{2 \tau}\right) \\
& \cdot \cos \left(\frac{n \pi}{\tau}(x-\theta-\varepsilon)\right) .
\end{aligned}
$$

As shown in Figure 3 for an axially magnetized, internal magnet machine topology, the effect of the slot openings may be accounted for by introducing a Carter factor $K_{C}$ given by [10]

$$
K_{C}=\frac{T_{t}}{T_{t}-\gamma g^{\prime}}
$$

where $T_{t}$ is the armature slot pitch (see Table 1), $g^{\prime}$ has been derived from (B.1), and the slotting coefficient $\gamma$ is computed by

$$
\gamma=\frac{4}{\pi}\left\{\frac{b_{o}}{2 g^{\prime}} \tan ^{-1}\left(\frac{b_{o}}{2 g^{\prime}}\right)-\ln \sqrt{1+\left(\frac{b_{o}}{2 g^{\prime}}\right)^{2}}\right\},
$$

where $b_{o}$ is the width of the armature slot openings. Thereafter, the effective airgap $g_{e}$ and effective air-gap computational radius $R_{\mathrm{se}}$ are given, respectively, by

$$
\begin{aligned}
g_{e} & =g+\left(K_{C}-1\right) g^{\prime}, \\
R_{\text {se }} & =R_{o}+g_{e} .
\end{aligned}
$$

\section{Definition of the Slot-Effect \\ Electromagnetic Energy $W_{\text {slot }}$ and the End- Effect Electromagnetic Energy $W_{\text {end }}$}

$W_{\text {slot }}$ is derived from the sum of the electromagnetic energy on the each tooth, as computed by

$$
\begin{aligned}
& W_{\text {slot }}=\frac{1}{2 \mu_{0}} \int_{R_{o}}^{R_{o}+g} 2 \pi r d r \\
& \cdot \sum_{i=0,1,2,3,4}\left(\int_{d_{s} / 2+i T_{t}}^{d_{s} / 2+w_{t}+i T_{t}}+\int_{T_{t}-d_{s} / 2-W_{t}+i T_{t}}^{T_{t}-d_{s} / 2+i T_{t}}\right) \\
& \cdot\left(B_{g}(x, \theta)\right)^{2} d x
\end{aligned}
$$

where $i$ is defined in (5) and $B_{g}(x, \theta)$ is the air-gap flux density which is calculated by (C.1)-(C.3).
$W_{\text {end }}$ is derived from the sum of the electromagnetic energy on the two ends of the stator, as calculated by

$$
\begin{aligned}
W_{\text {end }}= & \frac{1}{2 \mu_{0}} \int_{R_{o}}^{R_{o}+K_{\mathrm{O}} g} 2 \pi r d r\left(\int_{-\infty}^{d_{s} / 2}+\int_{d_{s} / 2+L}^{\infty}\right) \\
& \cdot\left(\lambda_{\text {end }}(x) B_{\text {pm-slotless }}(x, \theta)\right)^{2} d x,
\end{aligned}
$$

where $L$ (see Table 1 ) is the length of the stator section, as is shown in Figure $1(\mathrm{~b}) . \lambda_{\text {end }}(x)$ is the air-gap relative permeance on the two axially ends of the stator, as is shown by

$$
\lambda_{\text {end }}(x)= \begin{cases}e^{\left(x-d_{s} / 2\right) / 2 g_{e}} ; & x \leq \frac{d_{s}}{2} \\ 1 ; & \frac{d_{s}}{2}<x<\frac{d_{s}}{2}+L \\ e^{-\left(\left(x+d_{s} / 2+L\right) / 2 g_{e}\right)} ; & x \geq \frac{d_{s}}{2}+L .\end{cases}
$$

Then, combining (15), with (D.1)-(D.3), the analytical formulae of detent force is computed by

$$
\begin{aligned}
& F_{\text {detent }}(\theta)=F_{\text {slot }}(\theta)+F_{\text {end }}(\theta) \\
& =-0.19478 \times 10^{-3} \\
& \times \cos \left(1256.6 \times\left(\theta+\frac{T_{t}}{2}\right)\right)-0.9739 \\
& \times 10^{-3} \times \sin \left(1256.6 \times\left(\theta+\frac{T_{t}}{2}\right)\right) \\
& -6.9245 \times 10^{-9} \\
& \times \sin \left(1047.2 \times\left(\theta+\frac{T_{t}}{2}\right)\right)-1.6441 \\
& \times 10^{-8} \times \sin \left(1256.6 \times\left(\theta+\frac{T_{t}}{2}\right)\right) \\
& +9.9405 \times 10^{-9} \\
& \times \sin \left(9.4248 \times 10^{-8} \times\left(\theta+\frac{T_{t}}{2}\right)\right) \\
& -5.296 \times 10^{-10} \\
& \times \sin \left(3.1416 \times 10^{-8} \times\left(\theta+\frac{T_{t}}{2}\right)\right) \\
& -5.177 \times 10^{-10} \\
& \times \sin \left(2094.4 \times\left(\theta+\frac{T_{t}}{2}\right)\right)-2.698 \\
& \times 10^{-9} \\
& \times \sin \left(2.199 \times 10^{-7} \times\left(\theta+\frac{T_{t}}{2}\right)\right) \\
& -0.292 \times 10^{-5}
\end{aligned}
$$




$$
\begin{aligned}
& \times \cos \left(1885 \times\left(\theta+\frac{T_{t}}{2}\right)\right)-0.292 \\
& \times 10^{-5} \times \cos \left(1885 \times\left(\theta+\frac{T_{t}}{2}\right)\right) \\
& -0.39 \times 10^{-3} \\
& \times \sin \left(418.88 \times\left(\theta+\frac{T_{t}}{2}\right)\right)-0.9739 \\
& \times 10^{-3} \times \sin \left(837.8 \times\left(\theta+\frac{T_{t}}{2}\right)\right) \\
& -0.9739 \times 10^{-3} \\
& \times \sin \left(837.8 \times\left(\theta+\frac{T_{t}}{2}\right)\right)-0.39 \\
& \times 10^{-3} \times \cos \left(209.44 \times\left(\theta+\frac{T_{t}}{2}\right)\right) \\
& +3.14 \times 10^{-9} \\
& \times \sin \left(209.44 \times\left(\theta+\frac{T_{t}}{2}\right)\right)-46.6466 \\
& \times \sin \left(\frac{2 \pi\left(\theta+T_{t} / 2\right)}{\tau}\right)
\end{aligned}
$$

\section{E. Detailed Calculations for the Mathematical Model Parameters}

Seen from the five-phase Park transformation matrix $T(\theta)$, the following relation can be obtained:

$$
T^{-1}(\theta)=\frac{5}{2} T^{T}(\theta)
$$

where $T^{-1}(\theta)$ and $T^{T}(\theta)$ represent the inverse matrix and matrix transposition of $T(\theta)$, respectively.

Applying $T(\theta)$ to (11), the direct-axis and quadrature-axis voltage, $V_{d}$ and $V_{q}$, and the direct-axis and quadrature-axis currents. $i_{d}$ and $i_{q}$, are derived from

$$
\begin{aligned}
T(\theta) V_{s}= & T(\theta) R_{s} i_{s}+T(\theta) \frac{d \Lambda_{s}}{d t} \\
= & T(\theta) R_{s} T^{-1}(\theta) T(\theta) i_{s}+\frac{d}{d t}\left[T(\theta) \Lambda_{s}\right] \\
& -\frac{d T(\theta)}{d t} T^{-1}(\theta)\left[T(\theta) \Lambda_{s}\right],
\end{aligned}
$$

where

$$
\begin{aligned}
T(\theta) \Lambda_{s} & =T(\theta) L_{s s} T^{-1}(\theta) T(\theta) i_{s}+T(\theta) \psi_{m} \\
& =\Lambda_{d q s} .
\end{aligned}
$$

When the harmonics of the inductances are ignored, the direct-axis and quadrature-axis inductances are as follows:

$$
T(\theta) L_{\mathrm{ss}} T^{-1}(\theta)=\left[\begin{array}{lllll}
L_{d} & & & & \\
& L_{q} & & \\
& & 0 & & \\
& & & 0 & \\
& & & & 0
\end{array}\right],
$$

where

$$
\begin{aligned}
L_{d} & =\frac{5}{2} \mu_{0} R_{\mathrm{se}} M^{2} p \tau\left(2 G_{0}+G_{2}\right), \\
L_{q} & =\frac{5}{2} \mu_{0} R_{\mathrm{se}} M^{2} p \tau\left(2 G_{0}-G_{2}\right) .
\end{aligned}
$$

The permanent magnet flux linkages using the five-phase Park transformation matrix $T(\theta)$ are obtained by

$$
T(\theta) \psi_{m}=\psi_{m}^{\prime}[1,0,0,0,0]^{T} .
$$

The amplitude of the permanent magnet flux linkages is given by

$$
\psi_{m}^{\prime}=M B_{1} p \tau \pi R_{\mathrm{se}} g^{\prime}\left(2 G_{0}+G_{2}\right),
$$

where $M$ represents the fundamental amplitude of the modified winding function and it is given by

$$
M=\frac{4 N y_{w 1}}{p \pi} \sin \left(\frac{w_{c} \pi}{2 \tau}\right) .
$$

\section{Competing Interests}

The authors declare that there is no conflict of interests regarding the publication of this manuscript.

\section{References}

[1] I. Boldea and S. A. Nasar, "Linear electric actuators and generators," IEEE Transactions on Energy Conversion, vol. 14, no. 3, pp. 712-717, 1999.

[2] K.-H. Shin, M.-G. Park, H.-W. Cho, and J.-Y. Choi, "Comparative study of armature reaction field analysis for tubular linear machine with axially magnetized single-sided and doublesided permanent magnet based on analytical field calculations," Journal of Magnetics, vol. 20, no. 1, pp. 79-85, 2015.

[3] J. Wang and D. Howe, "Tubular modular permanent-magnet machines equipped with quasi-Halbach magnetized magnetspart I: magnetic field distribution, EMF, and thrust force," IEEE Transactions on Magnetics, vol. 41, no. 9, pp. 2470-2478, 2005.

[4] F. A. B. Kou, S. B. L. Li, and T. C. C. Zhang, "Analysis and optimization of thrust characteristics of tubular linear electromagnetic launcher for space-use," IEEE Transactions on Magnetics, vol. 45, no. 1, pp. 1-6, 2008.

[5] Y.-K. Kim, B.-G. Gu, I.-S. Jung, S.-H. Won, and J. Hur, "Analysis and design of slotted tubular linear actuator for the eco-pedal system of a vehicle," IEEE Transactions on Magnetics, vol. 48, no. 2, pp. 939-942, 2012. 
[6] N. R. Tavana and A. Shoulaie, "Pole-shape optimization of permanent-magnet linear synchronous motor for reduction of thrust ripple," Energy Conversion and Management, vol. 52, no. 1, pp. 349-354, 2011.

[7] D. Deás, P. Kuo-Peng, N. Sadowski, A. M. Oliveira, J. L. Roel, and J. P. A. Bastos, "2-D FEM modeling of the tubular linear induction motor taking into account the movement," IEEE Transactions on Magnetics, vol. 38, no. 2, pp. 1165-1168, 2002.

[8] N. Bianchi, "Analytical field computation of a tubular permanent-magnet linear motor," IEEE Transactions on Magnetics, vol. 36, no. 5, pp. 3798-3801, 2000.

[9] J. Wang, D. Howe, and G. W. Jewell, "Analysis and design optimization of an improved axially magnetized tubular permanent-magnet machine," IEEE Transactions on Energy Conversion, vol. 19, no. 2, pp. 289-295, 2004.

[10] J. Wang, G. W. Jewell, and D. Howe, "A general framework for the analysis and design of tubular linear permanent magnet machines," IEEE Transactions on Magnetics, vol. 35, no. 3, pp. 1986-2000, 1999.

[11] J. Wang, Z. Lin, and D. Howe, "Analysis of a short-stroke, singlephase, quasi-Halbach magnetised tubular permanent magnet motor for linear compressor applications," IET Electric Power Applications, vol. 2, no. 3, pp. 193-200, 2008.

[12] B. Tomczuk and A. J. Waindok, "A coupled field-circuit model of a 5-phase permanent magnet tubular linear motor," Archives of Electrical Engineering, vol. 60, no. 1, pp. 5-14, 2011.

[13] T. Lubin, T. Hamiti, H. Razik, and A. Rezzoug, "Comparison between finite-element analysis and winding function theory for inductances and torque calculation of a synchronous reluctance machine," IEEE Transactions on Magnetics, vol. 43, no. 8, pp. 3406-3410, 2007.

[14] S. Saied, K. Abbaszadeh, and A. Tenconi, "Improvement to winding function theory for PM machine analysis," in Proceedings of the 3rd IEEE International Conference on Power Engineering, Energy and Electrical Drives (PowerEng '11), pp. 1-6, Málaga, Spain, May 2011.

[15] A. Waindok and M. Piegza, "Tests of the controllers settings for a 5-phase permanent magnet tubular linear motor using Matlab/Simulink software," in Proceedings of the International Symposium on Electrodynamic and Mechatronic Systems (SELM '13), pp. 53-54, Zawiercie, Poland, May 2013.

[16] A. Waindok, "Modeling and measurement of transients for a 5-phase permanent magnet tubular linear actuator including control and supply system," Solid State Phenomena, vol. 214, pp. 121-129, 2014.

[17] N. A. Al-Nuaim and H. A. Toliyat, "A novel method for modeling dynamic air-gap eccentricity in synchronous machines based on modified winding function theory," IEEE Transactions on Energy Conversion, vol. 13, no. 2, pp. 156-162, 1998.

[18] L. Serrano-Iribarnegaray, P. Cruz-Romero, and A. GómezExpósito, "Critical review of the modified winding function theory," Progress in Electromagnetics Research, vol. 133, pp. 515534, 2013.

[19] S. Jordan, C. D. Manolopoulos, and J. M. Apsley, "Winding configurations for five-phase synchronous generators with diode rectifiers," IEEE Transactions on Industrial Electronics, vol. 63, no. 1, pp. 517-525, 2016.

[20] P. C. Krause, O. Wasynczuk, S. D. Sudhoff, and S. Pekarek, Analysis of Electric Machinery and Drive Systems, vol. 75, WileyIEEE Press, Piscataway, NJ, USA, 2013.

[21] N. Bianchi, S. Bolognani, D. D. A. Corte, and F. Tonel, "Tubular linear permanent magnet motors: an overall comparison," IEEE
Transactions on Industry Applications, vol. 39, no. 2, pp. 466475, 2003.

[22] Z. Q. Zhu and D. Howe, "Instantaneous magnetic field distribution in brushless permanent magnet DC motors. III. Effect of stator slotting," IEEE Transactions on Magnetics, vol. 29, no. 1, pp. 143-151, 1993.

[23] S. Nandi, H. A. Toliyat, and A. G. Parlos, "Performance analysis of a single phase induction motor under eccentric conditions," in Proceedings of the IEEE-IAS Annual Meeting, pp. 174-181, 1997.

[24] W. Xin-Huan, Z. Hong-Wei, and K. Run-Sheng, "Research on modeling and simulation of permanent magnet linear synchronous motor for vertical transportation system," in Proceedings of the Chinese Control and Decision Conference (CCDC '09), pp. 3332-3336, July 2009.

[25] G. Remy, G. Krebs, A. Tounzi, and P.-J. Barre, "Finite element analysis of a PMLSM (part 2)-cogging force and end-effect force calculations," in Proceedings of the 6th International Symposium on Linear Drives for Industry Applications (LDIA '07), Lille, France, September 2007.

[26] D. Žarko, D. Ban, and T. A. Lipo, "Analytical calculation of magnetic field distribution in the slotted air gap of a surface permanent-magnet motor using complex relative air-gap permeance," IEEE Transactions on Magnetics, vol. 42, no. 7, pp. $1828-1837,2006$

[27] P. Pillay and R. Krishnan, "Modeling, simulation, and analysis of permanent-magnet motor drives. I. The permanent-magnet synchronous motor drive," IEEE Transactions on Industry Applications, vol. 25, no. 2, pp. 265-273, 1989.

[28] L. Parsa and H. A. Toliyat, "Five-phase permanent-magnet motor drives," IEEE Transactions on Industry Applications, vol. 41, no. 1, pp. 30-37, 2005.

[29] G. J. Li, Z. Q. Zhu, W. Q. Chu, M. P. Foster, and D. A. Stone, "Influence of flux gaps on electromagnetic performance of novel modular PM machines," IEEE Transactions on Energy Conversion, vol. 29, no. 3, pp. 716-726, 2014.

[30] J. Wang and D. Howe, "Tubular modular permanent-magnet machines equipped with quasi-Halbach magnetized magnetspart I: Magnetic field distribution, EMF, and thrust force," IEEE Transactions on Magnetics, vol. 41, no. 9, pp. 2470-2478, 2005. 


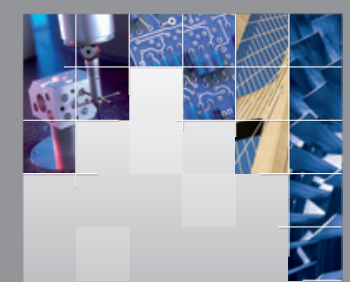

\section{Enfincering}
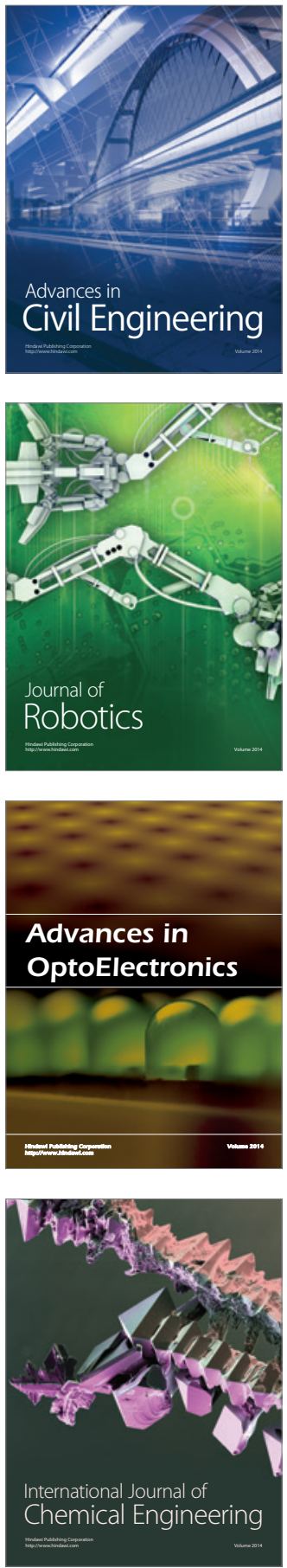

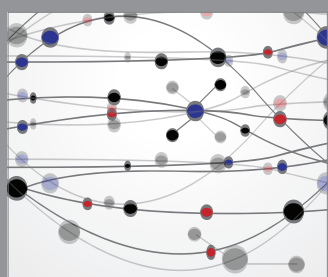

The Scientific World Journal

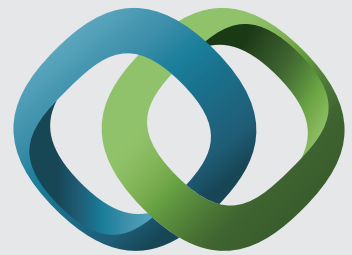

\section{Hindawi}

Submit your manuscripts at

http://www.hindawi.com
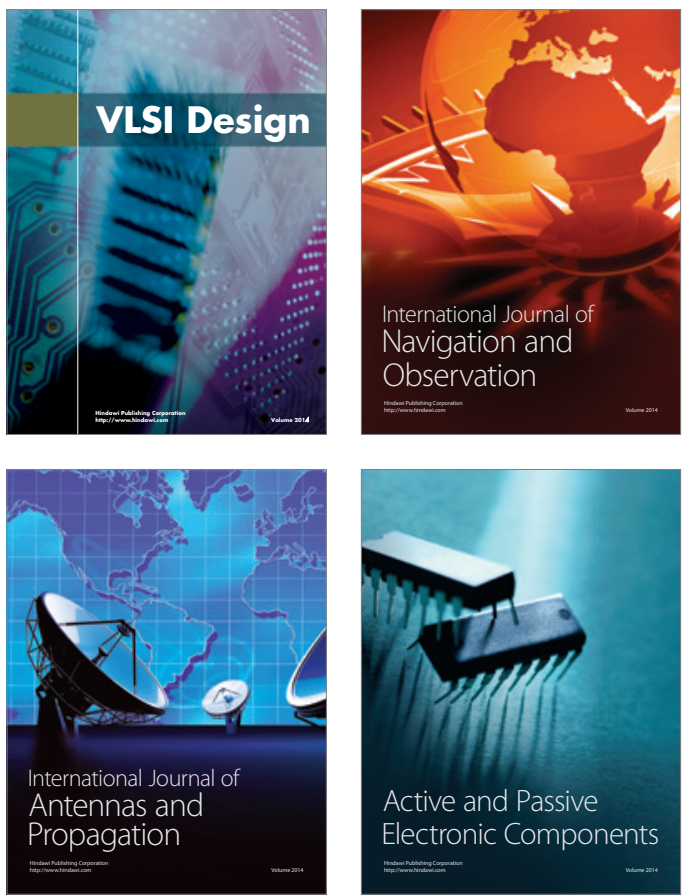
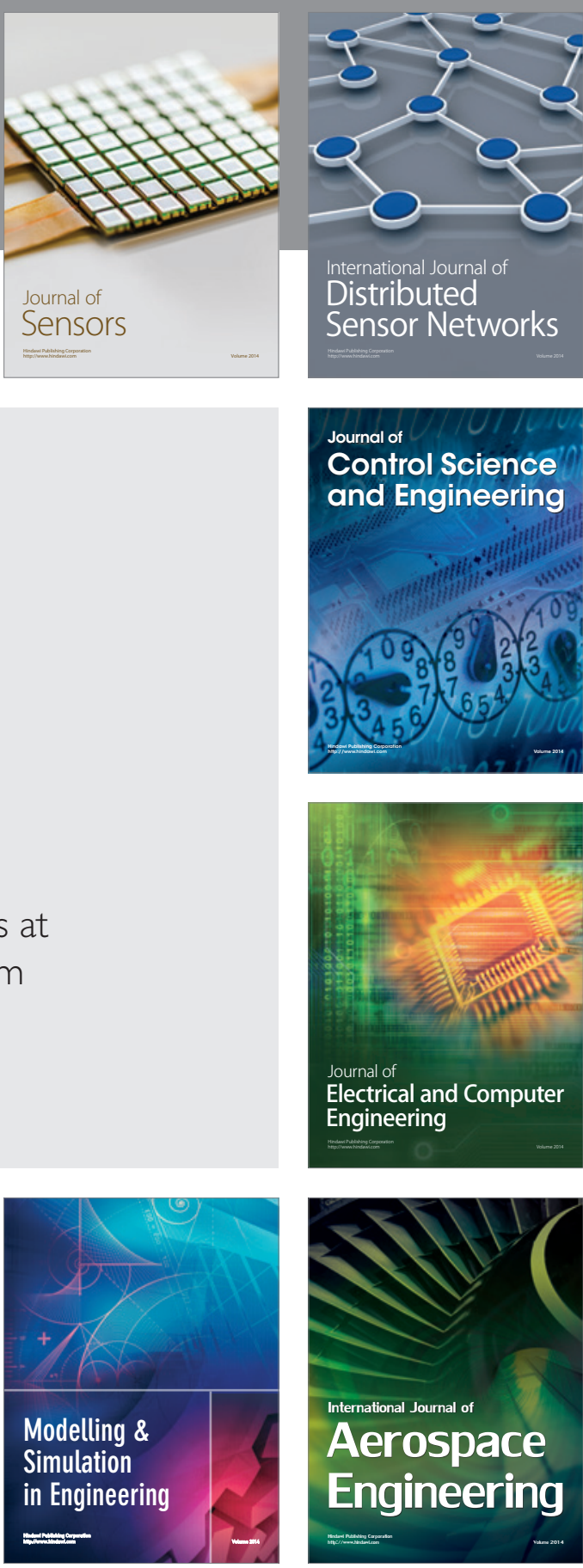

International Journal of

Distributed

Sensor Networks

Journal of

Control Science

and Engineering
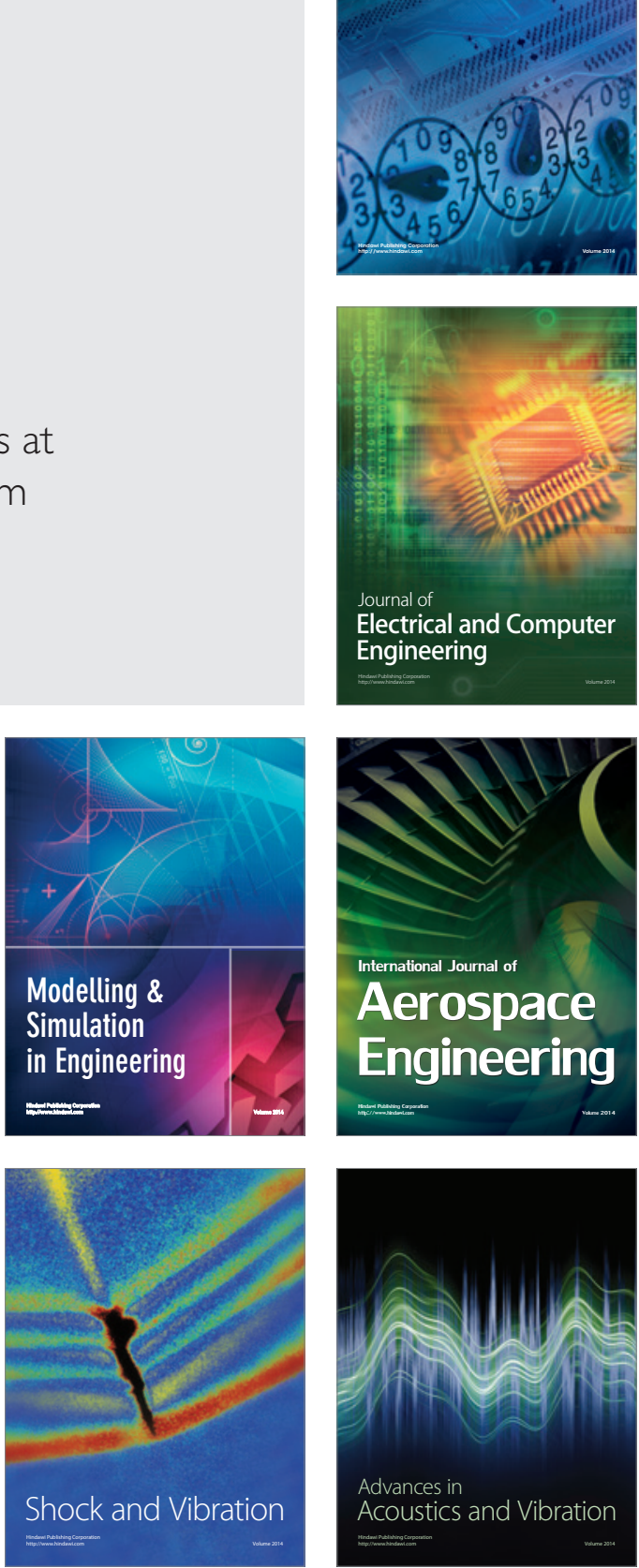